\title{
Birth Weight for Gestational Age Centile Charts for Low-risk Population of Islamabad Capital Territory: A Hospital-based Study and Cross-country Comparison
}

\author{
${ }^{1}$ Nasira Tasnim, ${ }^{2}$ Ayesha Hanif, ${ }^{3}$ Hadia Aziz
}

\begin{abstract}
Objective: To establish birth weight percentile charts for gestational age based on prospectively collected data for Islamabad Capital Territory (ICT) urban/rural low-risk population presenting at Mother and Child Health (MCH) Center, Pakistan Institute of Medical Sciences (PIMS), Islamabad, Pakistan, and crosscountry comparison.
\end{abstract}

Place and duration of study: The study was conducted for a period of 6 months (January 2014-June 2014) at MCH Center Unit II, Shaheed Zulfiqar Ali Bhutto Medical University, Pakistan Institute of Medical Sciences (SZABMU-PIMS), Islamabad, Pakistan.

\section{Study design: Comparative cross-sectional study.}

Materials and methods: Data of low-risk women from ICT urban/rural population presenting at $\mathrm{MCH}$ Center, PIMS were prospectively maintained, entered in Excel sheet, and later analyzed using Statistical Package for the Social Sciences version 21. The confounding factors that affect the fetal growth including gestational diabetes, hypertension, history of intrauterine growth restriction, and medical disorders were excluded.

The 5th, 10th, 50th, 90th, and 95th centile birth weight charts were calculated for gestational age between 32 and 41 weeks and were compared with those of other countries. The gestational age was calculated by clinical obstetrician or estimates by early ultrasound if available.

Results: A total of 1,744 singleton live births were analyzed. The birth weights at 5th, 10th, 50th, 90th, and 95th centile were calculated at 32 to 41 weeks of gestation. Cross-country comparison of birth weight at 50th centile of ICT population is comparable with other countries till 37 weeks and lower after 37 weeks, except Indian population. The birth weight at 90th centile at all gestations (32-41 weeks) was comparable with other populations. However, the birth weight at 10th centile for ICT population is far below than the other countries except Indian population.

\section{${ }^{1}$ Professor and Head, ${ }^{2,3}$ Postgraduate Resident}

${ }^{1}$ Mother and Child Health Center, Unit II, Shaheed Zulfiqar Ali Bhutto Medical University, Pakistan Institute of Medical Sciences Islamabad, Pakistan

${ }^{2,3}$ Department of Obstetrics and Gynaecology, Mother and Child Health Center, Unit II, Shaheed Zulfiqar Ali Bhutto Medical University, Pakistan Institute of Medical Sciences, Islamabad Pakistan

Corresponding Author: Nasira Tasnim, House No. 773, Service Road West, I-8/2, Islamabad, Pakistan, Phone: +0306-5229391 e-mail: mchunit2@gmail.com
Conclusion: The updated birth weight for gestational age centile charts may be utilized as reference charts for ICT population and may be extrapolated to Pakistani population until the availability of national database.

Keywords: Birth weight, Centile charts, Small for gestational age.

How to cite this article: Tasnim N, Hanif A, Aziz $\mathrm{H}$. Birth Weight for Gestational Age Centile Charts for Low-risk Population of Islamabad Capital Territory: A Hospital-based Study and Cross-country Comparison. J South Asian Feder Obst Gynae 2017;9(2):169-172.

Source of support: Nil

Conflict of interest: None

Date of received: 18 January 2017

Date of acceptance: 8 March 2017

Date of publication: April 2017

\section{INTRODUCTION}

Birth weight by gestational age is the key determinant of the health of neonate at birth and its outcome. On one end of the spectrum are growth-restricted neonates $(<10$ th centile) whose further needs are based on the birth weight. They are at increased risk of perinatal asphyxia and its sequelae, congenital malformation, hypoglycemia, and pulmonary hemorrhage. ${ }^{1}$ After the control of the effects of the gestational age, birth weight alone has been found to have strong association with perinatal survival in such fetuses. ${ }^{2}$ On the other end of the spectrum lie infants who are larger for gestational age ( $>90$ th centile) where risk of mother suffering from diabetes is a major issue. The planning for mode of delivery in subsequent pregnancy is also based on the birth weight of the preexisting child. The various classification systems exist for birth weight gestational age categories. Some investigators have used mean \pm standard deviation charts; however, most have used the percentile chart of the birth weight for each completed week of gestation.

Several standardized charts have been published in developed countries and in some of the developing countries, but there is scarcity of data in Pakistani population. A few local studies based on fetal biometry show that European and American standardized charts cannot be generalized to our population. ${ }^{3,4}$ However, 
these studies are based on sonographic models and do not represent the actual birth weight. Thus, there is a need to establish percentile charts of birth weight for gestational age within our local population. This will also help to form a baseline data for epidemiological studies for factors that may contribute to size of babies for individual gestational age.

\section{MATERIALS AND METHODS}

The medical records of infants born at MCH Center, PIMS Unit II, from January 2014 to June 2014 between 32 and 41 weeks were reviewed. The gestational age was based on last menstrual period (LMP) and on early ultrasound if available. The high-risk cases as well as those with major congenital malformation, stillbirth, twin pregnancy, uncertain gestational age, and incomplete data were excluded from the study. The birth weights were measured on digital weighing machine with a variability of $\pm 10 \mathrm{gm}$. The data were entered in Excel sheet and were analyzed through Statistical Package for the Social Sciences version 21. Descriptive statistics were used for analysis. Mean, median, and mode were calculated for

Table 1: Birth weight centiles of ICT at various gestational ages

\begin{tabular}{lllllll}
\hline Gestational age & $N$ & 5 th & 10th & 50th & 90th & 95th \\
\hline 32 & 80 & 0.500 & 0.800 & 1.800 & 3.000 & 3.395 \\
33 & 23 & 1.020 & 1.180 & 2.100 & 2.920 & 3.000 \\
34 & 48 & 1.000 & 1.200 & 2.400 & 3.20 & 3.510 \\
35 & 65 & 1.500 & 1.800 & 2.500 & 3.040 & 3.200 \\
36 & 173 & 2.070 & 2.200 & 3.000 & 3.500 & 3.730 \\
37 & 197 & 2.000 & 2.300 & 3.000 & 3.520 & 3.810 \\
38 & 384 & 2.125 & 2.500 & 3.000 & 3.650 & 3.900 \\
39 & 382 & 2.315 & 2.500 & 3.000 & 3.770 & 3.900 \\
40 & 306 & 2.500 & 2.600 & 3.200 & 3.900 & 4.000 \\
41 & 86 & 2.400 & 2.670 & 3.150 & 3.800 & 3.965 \\
\hline
\end{tabular}

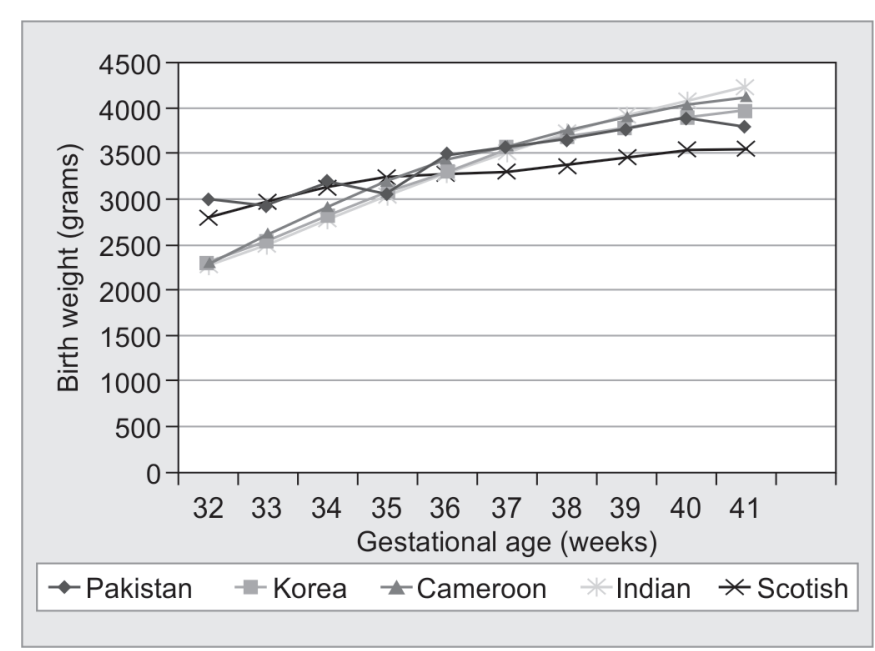

Graph 2: Cross-country comparison of birth weight at 90th centile individual gestational age groups. The 5th 10th, 50th, 90th, and 95th centiles were calculated and compared with centile charts of other countries.

\section{RESULTS}

During 6-month study period, from January to June 2014, 4,650 patients were delivered. Of these, 96 were stillbirths, while 4,554 were live births. Of these, 2,501 were high-risk patients and were excluded from the study. The remaining 2,053 live born, low-risk singleton babies were considered for analysis. After excluding the cases with missing information, 1,744 were finally analyzed.

Mean maternal age was $26.54 \pm 4.7$ years. Of these, $1,024(58.4 \%)$ were para $1 ; 637(34.5 \%)$ were para $2 ; 80$ $(7 \%)$ were para 3 , while $3(0.1 \%)$ were para 4 or more. The various centiles for the study population are shown in Table 1, while the cross-country comparison of 10th, 50th, and 90th centile is shown in Graphs 1 to 3 respectively. Referring Graph 1, birth weight at 50th centile of Islamabad Capital Territory (ICT) population was comparable

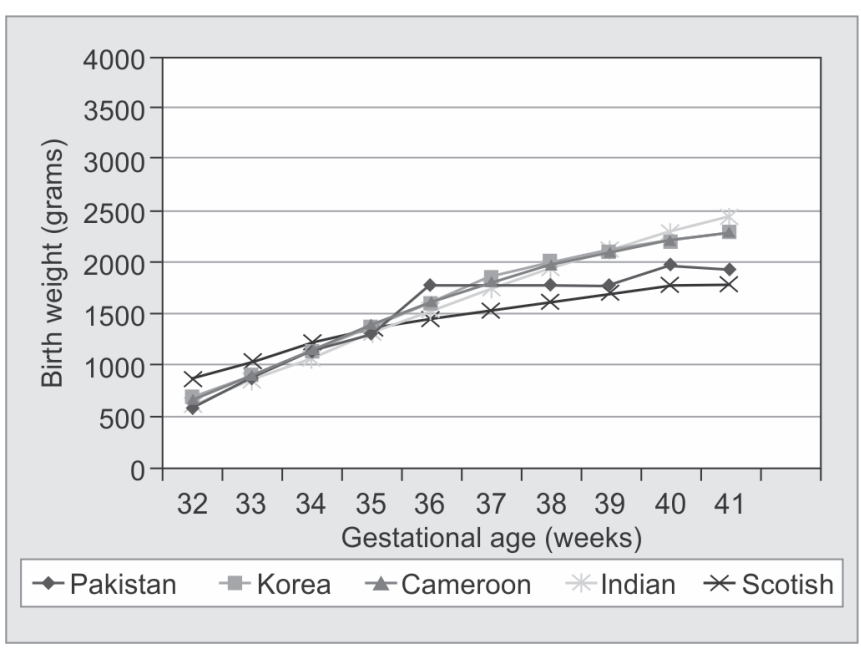

Graph 1: Cross-country comparison of birth weight at 50th centile

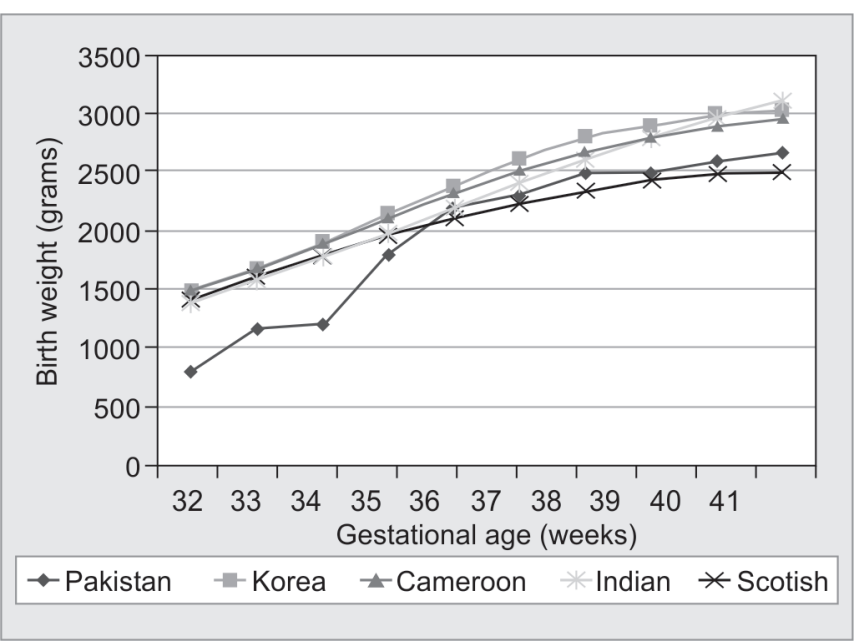

Graph 3: Cross-country comparison of birth weight at 10th centile 
with the Korean, Cameroon, Indian, and Scottish population till 37 weeks gestation. However, after 37 weeks, birth weights were found lower than the others except Indian population. Referring Graph 2, the birth weights at 90th centile were found to range from 3,000 gm at 32 weeks to 3,800 gm at 41 weeks of gestation, which was found similar to 90th centile of the studies from other countries.

Referring Graph 3, the birth weight at 10th centile was lower than the rest of the populations at all gestations from 32 to 41 weeks. However, they were found higher than Indian population after 37 weeks of gestation.

\section{DISCUSSION}

The study provides useful information for future epidemiological studies. It also provides important information to clinicians as to which babies are at high risk of neonatal morbidity by virtue of categorizing them into appropriate for gestational age, small for gestational age (SGA), and large for gestational age. The study findings reveal that the 50th centile of birth weight for ICT population was comparable with the Korean, Cameroon, Indian, and Scottish population till 37 weeks gestation. However, after 37 weeks a lower trend was found compared with others except Indian population. ${ }^{5-8}$ Though exact justification is difficult in this regard, ethnic differences seem to play a role to determine the birth weight at term, as has been shown by other authors. ${ }^{9}$

The 90th centile of ICT population was found to range from 3,000 gm at 32 weeks to 3,800 gm at 41 weeks gestation, which is comparable to other countries. It is important to point out that most of the epidemiological and clinical studies label the baby weighing more than 4,000 gm as "macrosomic babies," as they are at a higher frequency of adverse outcome as hypoglycemia (5.3 vs $2.6 \% ; \mathrm{p}=0.04$ ), respiratory distress syndrome ( 4.0 vs $1.5 \%$; $\mathrm{p}=0.03)$, shoulder dystocia (10.5 vs $1.6 \%$; $\mathrm{p}<0.001)$, and Erb's palsy (2.6 vs $0.2 \%$; p < 0.001). ${ }^{10}$ Our findings prompt new cutoff limit of 3,800 gm for defining fetal macrosomia. The new cutoff limits of defining fetal macrosomia may be utilized in clinical decision making.

The 10th centile of our study was found to range between 800 and 2,600 gm, which is far below the ones reported by other studies. ${ }^{5-8}$ As birth weight is one of the important parameter to determine the morbidity in terms of hypoglycemia, hypothermia, respiratory distress, and necrotizing enterocolitis, ${ }^{11,12}$ the findings of our study carry a significant clinical relevance: The risk of neonatal morbidity and mortality of our SGA babies is expected to be much higher than the other countries, thus highlighting the need for establishing neonatal intensive care units.

The study is limited by the fact that gestational age was based on LMP in majority of the patients, while ultrasound-based assessment was available in only a limited number of cases. This poses limitation in exact assessment of period of gestation. It has been observed that the knowledge of LMP differs by 14 days or more in almost $39.8 \%$ and 21 days or more in $30.1 \%$ of patients when compared with early ultrasound. Thus, longitudinal studies with recruitment of patients in the 1st trimester with the dating scan may prove useful due to better accuracy of period of gestation, as has been done in a few studies. ${ }^{13,14}$

Most of the studies that have developed birth weight for gestational age chart have utilized national database or were based on data from large samples of mothers recruited for a period of 5 years or more. ${ }^{13}$ Our study is limited by utilizing the small local data over a period of 6 months. However, it recruits both ICT urban and rural population and thus provides a baseline birth weight data for ICT population, which can be utilized for future reference in epidemiological and clinical studies until the availability of large data.

The study did not take into account the gender of the babies. Some of the studies have taken this aspect into consideration and have developed separate charts for the two genders. A study conducted by Parveen ${ }^{15}$ in this regard showed that the male babies were heavier than the female babies. The studies by other authors, however, showed that the observed differences between the two genders are not of much clinical significance. ${ }^{16}$

\section{CONCLUSION}

The updated birth weight for gestational age centile charts may be utilized as reference charts for ICT population and may be extrapolated to Pakistani population until the availability of national database.

\section{ACKNOWLEDGMENT}

Authors are grateful to their postgraduate residents for appropriate record keeping, Mr Mohammed Adnan, research assistant, for data entry and Mr Shafique Arif, Director Survey \& Field Research-Oxford Policy management, for data analysis.

\section{REFERENCES}

1. Sinclair, JC.; Tudehope, DJ. Birth weight, gestational age, and neonatal risk. In: Fanaroff AA, Martin RJ, Merkatz IR, editors. Behrman's neonatal - perinatal medicine: diseases of the fetus and infant. Toronto: Mosby; 1983. p. 196-205.

2. Wilcox AJ, Skjoerven R. Birth weight and perinatal mortality: the effect of gestational age. Am J Public Health 1992 Mar;82(3):378-382.

3. Shehzad K, Ali M, Zaidi S. Fetal biometry. Pak J Med Sci 2006;22:503-508.

4. Akhtar W, Ali A, Aslam M, Saeed F, Salman, Ahmad N. Birth weight estimation, a sonographic model for Pakistani population. J Pak Med Assoc 2010 Jul;60(7):517-520. 
5. Lim SJ, Lim WS, Ahn JH, Song BS, Shim KS, Hwang IT. New Korean reference for birth weight by gestational age and sex: data from the Korean statistical information service (20082012). Ann Pediatr Endocrinol Metab 2014 Sep;19(3):146-153.

6. Kemfang Ngowa JD, Domkam I, Ngassam A, NguefackTsague G, Dobgima Pisoh W, Noa C, Kasia JM. References of birth weights for gestational age and sex from a large cohort of singleton births in Cameroon. Obstet Gynecol Int 2014;2014:361451.

7. Alexender AM, George K, Muliyil J, Bose A, Prasad JH. Birth weight centile charts from rural community-based data from Southern India. Indian Pediatr 2013 Nov 8;50(11):1020-1024.

8. Bonellie S, Chalmers J, Gray R, Greer I, Jarvis S, Williams C. Centile charts for birth weight for gestational age for Scottish singleton births. BMC Pregnancy Childbirth 2008 Feb 25;8: $1-10$.

9. Brenner WE, Edelman DA, Hendricks CH. A standard of fetal growth for the United States of America. Am J Obstet Gynecol 1976 Nov 1;126(5):555-564.

10. Esakoff TF, Cheng YW, Sparks TN, Caughey AB. The association between birth weight $4000 \mathrm{~g}$ or greater and perinatal outcomes in patients with and without gestational diabetes mellitus. Am J Obstet Gynecol 2009 Jun;200(6):672.e1-672.e4.

11. Lubchenco LO, Hasman C, Dressler M, Boyd E. Intrauterine growth as estimated from live born birth weight data at 24 to 42 weeks of gestation. Pediatrics 1963 Nov;32:793-800.

12. Fenton TR. A new growth chart for preterm babies: Babson and Benda's chart updated with recent data and a new format. BMC Pediatr 2003 Dec 16;3:13.

13. Steemers N, Geerts L. Determination of gestational age: Is our estimation accurate? Abstracts of the 12th conference on priorities in perinatal care in South Africa. Mont-aux-Sources, Drakensberg, March 9-12, 1993.

14. Ruwanpathriana T, Fernnado DN, Senanayake H. Development of birth weight for gestational age charts in Sri Lankan setting methodological issues. WHO South-East Asia J Public Health 2013;2:47-53.

15. Parveen Z. Birth weight percentiles by gestational age: a hospital based study. J Ayub Mol Coll Abottabad 2001 AprJun;13(2):22-27.

16. Arbuckle TE, Sherman GJ. An analysis of birth weight by gestational age in Canada. CMJAJ 1989 Jan 15;140(2):158-161. 